\title{
Endoscopic transpapillary gallbladder stenting using a newly designed plastic stent for acute cholecystitis
}

\section{()(1) $\odot$}

\author{
Authors \\ Kazunari Nakahara ${ }^{1}$, Yosuke Michikawa ${ }^{1}$, Ryo Morita ${ }^{1}$, Keigo Suetani ${ }^{1}$, Nozomi Morita ${ }^{1}$, Junya Sato ${ }^{1}$, Kensuke Tsuji ${ }^{1}$, \\ Hiroki Ikeda ${ }^{1}$, Kotaro Matsunaga ${ }^{1}$, Tsunamasa Watanabe' ${ }^{1}$, Nobuyuki Matsumoto ${ }^{1}$, Shinjiro Kobayashi², Takehito \\ Otsubo $^{2}$, Fumio Itoh ${ }^{1}$
}

Institutions

1 Department of Gastroenterology and Hepatology, St. Marianna University, School of Medicine, Kawasaki, Japan

2 Department of Gastroenterological and General Surgery, St. Marianna University School of Medicine, Kawasaki, Japan

submitted 5.7.2018

accepted after revision 4.9.2018

\author{
Bibliography \\ DOI https://doi.org/10.1055/a-0747-5668 | \\ Endoscopy International Open 2019; 07: E1105-E1114 \\ (c) Georg Thieme Verlag KG Stuttgart · New York \\ eISSN 2196-9736
}

\section{Corresponding author}

Kazunari Nakahara, Department of Gastroenterology and Hepatology, St. Marianna University, School of Medicine, 2-16-1, Sugao, Miyamae-ku, Kawasaki, 216-8511, Japan Fax: +81-44-976-5805

nakahara@marianna-u.ac.jp

\section{ABSTRACT}

Background and study aims Biliary plastic stents are generally substituted for gallbladder stents in endoscopic transpapillary gallbladder stenting (EGBS), there is no sufficient evidence about what type of plastic stent is suitable. We examined outcomes of EGBS using standard biliary stents and a novel stent for acute cholecystitis and evaluated the efficacy of the novel stent.

Patients and methods Seventy patients with acute cholecystitis in whom EGBS was performed were evaluated retrospectively. We performed EGBS in 23 patients using the novel stent (novel stent group) and 47 patients using standard biliary stents (pigtail: 35 , straight: 12 ) (control group). In the two groups, we examined outcomes of EGBS.

Results There were no significant differences in patient backgrounds or rates of technical success, clinical success, or early adverse events (AE) between the novel stent group and the control groups. However, rates of late AEs were $4.3 \%$ in the novel stent group (liver abscess: 1 ) and $40.4 \%$ in the control group (stent migration: 15 , recurrence of cholecystitis: 4), indicating a significantly higher rate in the control group $(P=0.004)$. The rate of stent migration was significantly higher in the control group $(P=0.006)$. Multivariate analysis identified a straight type stent as the risk factor for stent migration (odds ratio: $8.81,95 \%$ confidence interval: $1.66-46.83$ ).

Conclusions The novel stent had significantly lower rates of late AEs and stent migration. Thus, for long-term stent placement, the novel stent was more effective than traditional biliary stents.

\section{Introduction}

Endoscopic transpapillary gallbladder drainage (ETGBD) has been reported to be effective for acute cholecystitis, for which emergency cholecystectomy and percutaneous transhepatic gallbladder drainage (PTGBD) are considered to be high risk because of coagulopathy, administration of antithrombotic drugs, and poor physical condition [1-5]. In previous reports, two types of ETGBD - endoscopic naso-gallbladder drainage
(ENGBD) and endoscopic gallbladder stenting (EGBS) - showed no difference in technical success, clinical success, or early adverse events (AEs) [6-9]. Although both types are suitable for treatment of acute cholecystitis, EGBS is considered to be superior in terms of patient quality of life [6].

In general, traditional biliary plastic stents are substituted for gallbladder stents in EGBS. However, there is no sufficient evidence about which type of plastic stent is suitable for EGBS, especially for long-term placement. Although standard biliary 
plastic stents have a straight shaft, gallbladder stents are placed with a deeper curve than biliary stents because of anatomical features. Thus, problems may be encountered, such as stent migration due to strong axial force and kinking at the bent portion. Moreover, because a longer stent is often needed for the gallbladder than for the bile duct, a traditional biliary stent may be too short for EGBS.

To overcome these problems, we developed a new design for a plastic stent for EGBS. In this study, we examined short- and long-term outcomes of EGBS using standard stents and the novel stent for acute cholecystitis and evaluated the efficacy of the novel stent.

\section{Patients and methods}

\section{Patients}

A total of 198 patients underwent ETGBD (117 males and $81 \mathrm{fe}$ males; age, $73.6 \pm 11.7$ years) (mean \pm standard deviation [SD]) for acute cholecystitis at St. Marianna University School of Medicine Hospital between March 2011 and September 2017. None of the patients were suitable candidates for emergency cholecystectomy and percutaneous transhepatic gallbladder drainage (PTGBD) because of high risk of coagulopathy, administration of antithrombotic drugs, poor physical condition, advanced age, or coexistence of choledocholithiasis. In terms of anatomy, 190 patients had normal stomachs, four had BillrothI reconstruction, three had Billroth-II reconstruction, and one had Roux-en-Y (R-Y) reconstruction. Although bile duct cannulation was unsuccessful in one patient and guidewire (GW) insertion into the gallbladder was unsuccessful in 20 patients, the GW could be placed into the gallbladder in 177 patients. In our hospital, after placing the GW into the gallbladder, a 7-Fr tapered catheter with side holes is inserted into the gallbladder to suction bile and irrigate it with saline. In two patients, insertion of the tapered catheter was impossible. Among the 175 patients in whom the tapered catheter could be inserted, 80 underwent ENGBD, 82 underwent EGBS, and 13 underwent endoscopic gallbladder aspiration.

Among the 82 patients who underwent EGBS, 12 patients in whom we use modified stent created by cutting various types of nasobiliary tube were excluded. In total, 70 patients in whom EGBS was performed using the newly designed stent or standard biliary stents (39 males and 31 females; age, $75.0 \pm$ 11.5 years) were selected as subjects and were evaluated retrospectively. After September 2016, we performed EGBS in 23 patients using the newly designed stent and classified these patients into the novel stent group. On the other hand, we defined 47 patients who underwent EGBS using standard biliary stents (double-pigtail type, 35; straight type, 12) before August 2016 prior to introduction of the newly designed stent as the control group ( $\triangleright$ Fig. 1 ).

\section{EGBS technique}

We used a duodenoscope (JF260V or TJF260V; Olympus Medical Systems, Tokyo, Japan) and performed bile duct cannulation by conventional contrast cannulation or wire-guided cannulation. After bile duct cannulation, a hydrophilic GW (e.g., Radi-

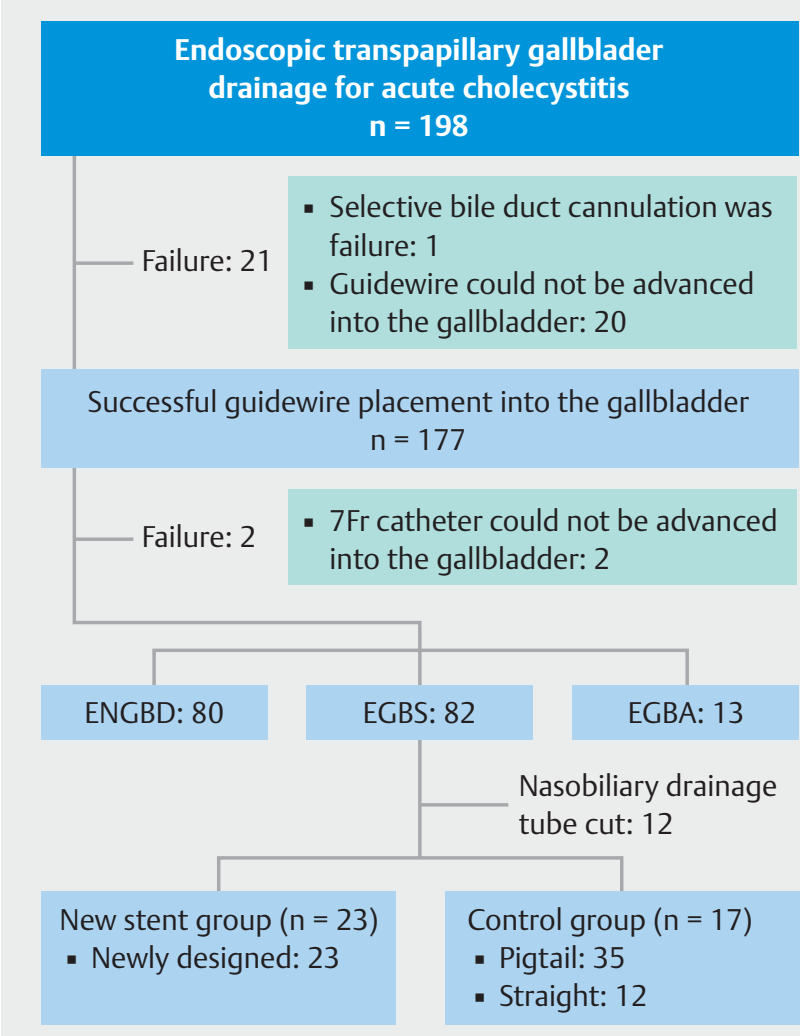

Fig. 1 Flowchart of the study.

focus, Terumo Co., Ltd., Tokyo, Japan) was passed through the cystic duct and inserted into the gallbladder. After changing the GW to a stiff type, we inserted a 7-Fr tapered catheter with side holes (CX-PTCD kit [PD-EN7F (ST) 180C4], Gadelius Medical, Tokyo, Japan) into the gallbladder over the GW, suctioned the bile, and subsequently irrigated the gallbladder with saline ( $\triangleright$ Fig. 2). Next, we measured the length from the papilla to the gallbladder using the GW and placed the stent so that the tip was at the fundus of the gallbladder.

All endoscopic retrograde cholangiopancreatography (ERCP) procedures were performed under the supervision of an expert who has performed more than 1000 such procedures. Gabexate mesylate was administered at a dosage of $600 \mathrm{mg} /$ day on the day of the procedure to all patients to prevent post-ERCP pancreatitis.

\section{Novel stent}

We developed a novel stent for EGBS (GBest-N stent; Hanaco Medical Co., Saitama, Japan) (\ Fig.3). The length of the novel stent has a variation of $11 \mathrm{~cm}, 13 \mathrm{~cm}, 15 \mathrm{~cm}, 17 \mathrm{~cm}$, and $19 \mathrm{~cm}$. The tip of the stent has a three-dimensional spiral-shaped structure, and there are side holes inside the spiral. The spiralshaped tip is expected to prevent migration of the stent. Further, by opening the side holes inside of the spiral part of the stent, it is anticipated that the side holes will not be obstructed even if the stent adheres to the contracted gallbladder wall and drainage will be maintained. The shaft of the stent is $7 \mathrm{Fr}$ and 

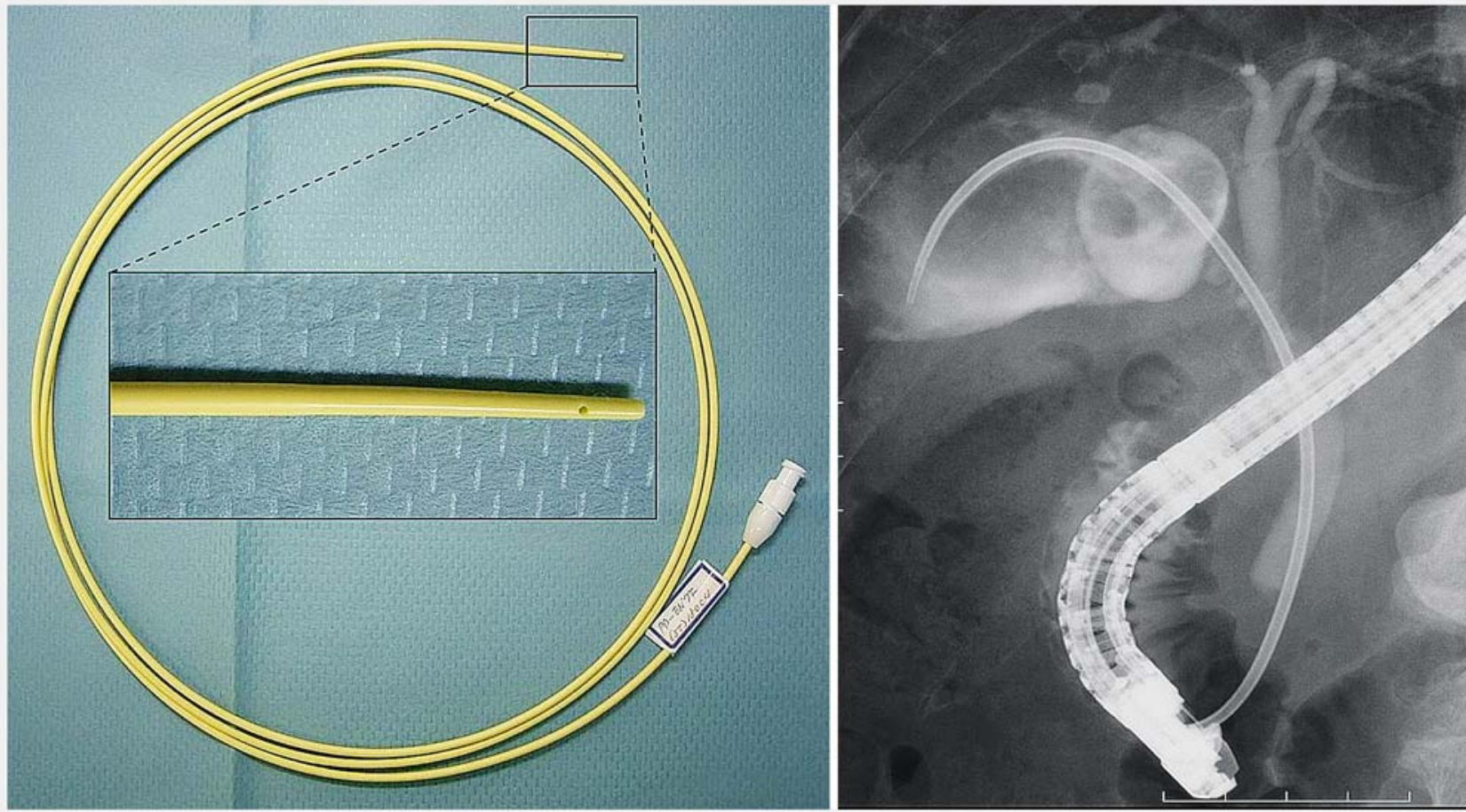

- Fig. 2 A 7-Fr tapered catheter with side holes is inserted into the gallbladder and suction the bile and irrigate with saline.

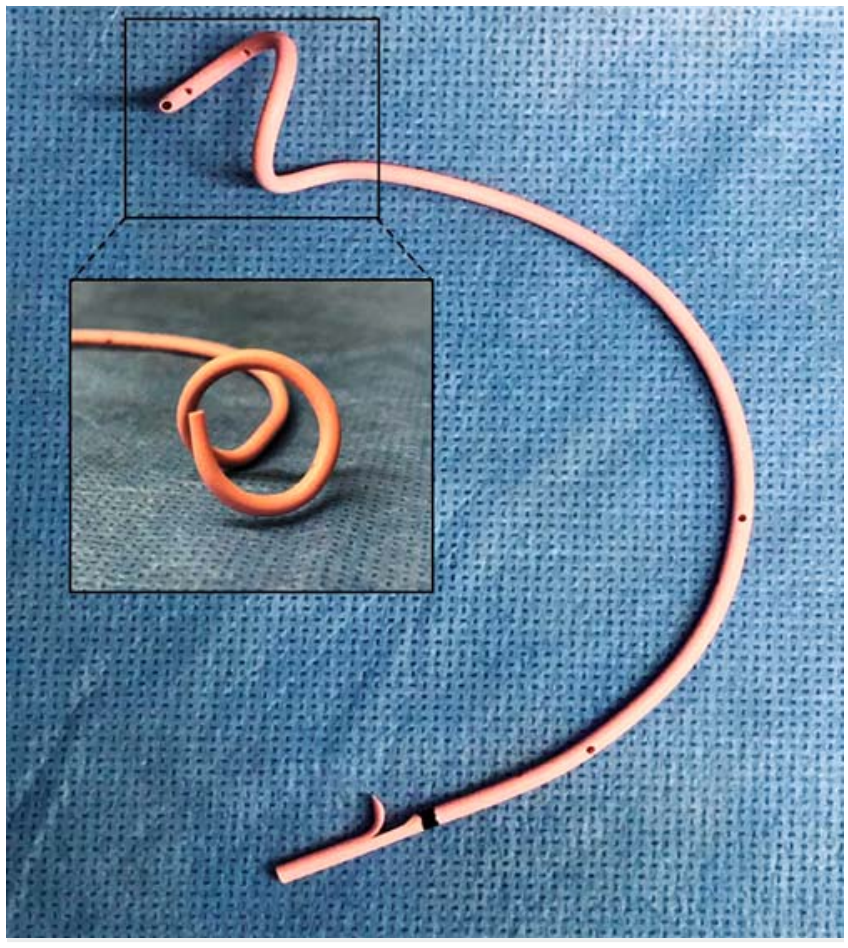

- Fig. 3 Newly designed gallbladder stent (GBest-N stent).

semicircular and it also has side holes. When inserted into the gallbladder, the stent is often placed in a curved manner because of the anatomical structure. Because the stent is semicir- cular, it fits well and is not expected to migrate because the axial force of the stent is reduced. In patients with abnormal coagulation, endoscopic sphincterotomy (EST) cannot be performed, and cholestasis could develop at the papilla. The side holes on the shaft are designed to drain the bile from the common bile duct. The distal side of the stent is straight, with a flap to prevent proximal migration. Fig. 4 shows placement of a novel stent into the gallbladder.

\section{Stents used in the control group}

The stents used in the control group were as follows: doublepigtail stents: 35 [Advanix (Boston Scientific, Natick, Massachusetts, United States): 16, SET-ERBD-72 stents (Hanaco Medical Co., Saitama, Japan): 12, CX-T stents (Gadelius Medical, Tokyo, Japan): 5, PBD-203 stent (Olympus Medical Systems, Tokyo, Japan): 1, and Zimmon biliary stent (Cook Japan, Tokyo, Japan): 1]; straight type stents: 12 [Through Pass (Gadelius Medical, Tokyo, Japan): 11 and CX-T stent (Gadelius Medical, Tokyo, Japan): 1].

\section{Measurements}

In the novel stent group and the control group, we retrospectively examined and compared the following: patient background, details of endoscopic procedures, technical success rate of EGBS, clinical success rate for acute cholecystitis, early AEs, and late AEs. Cholecystitis severity was determined according to the Tokyo Guidelines 2013 (TG13) for acute cholecystitis [10]. We defined technical success of EGBS as the tip of the stent remaining in the gallbladder and clinical success as 


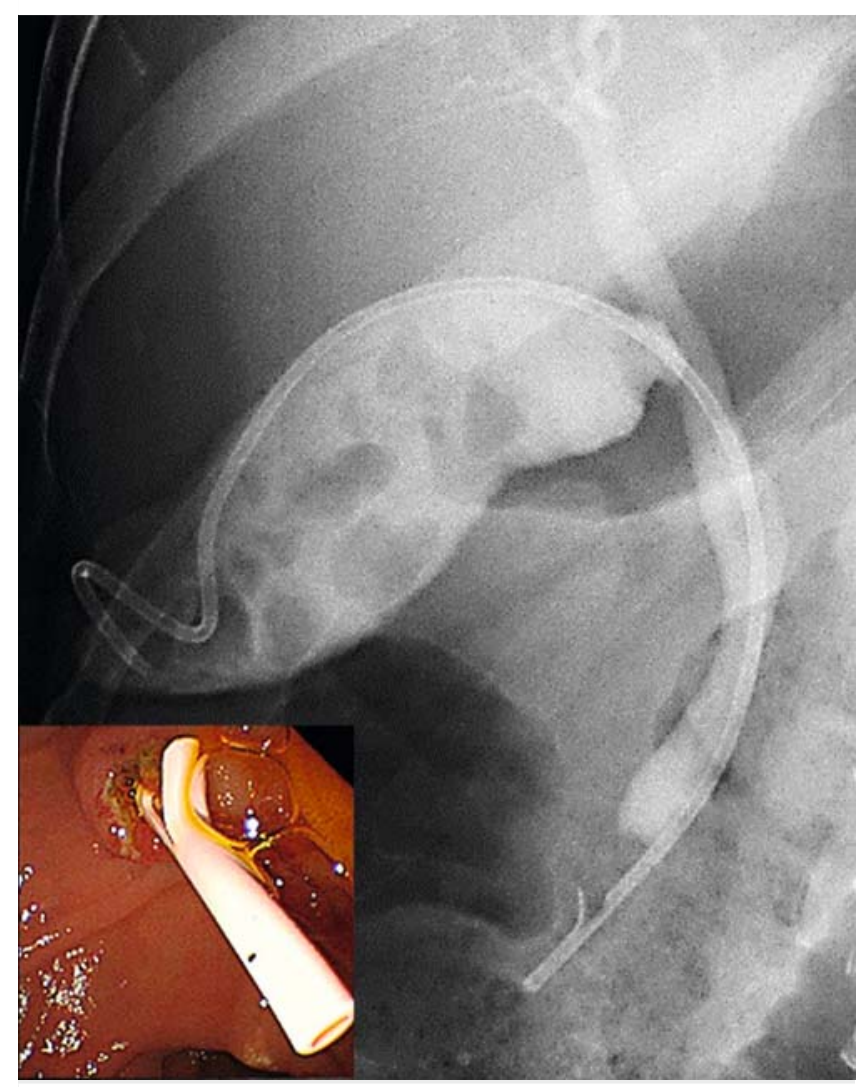

when clinical symptoms and laboratory test results showed an improving tendency within 3 days after EGBS. Early AEs were those that occurred within 7 days, and late AEs were those that occurred at least 8 days after EGBS. The diagnosis and severity of AEs included pancreatitis, bleeding, perforation, and cholangitis based on the consensus guidelines by Cotton et al. [11]. We defined as stent distal migration not only when the stent migrated to the intestine or out of the body but also when a large part of the stent tip slipped out of the gallbladder. Especially with a pigtail stent, migration was defined as when only the tip of the stent was caught in the neck of gallbladder or cystic duct ( $>$ Fig. 5 ).

This study was approved by the Institutional Review Board of St. Marianna University School of Medicine (approval number: 3891).

\section{Statistical analysis}

We used StatMate IV (ATMS Co., Ltd., Tokyo, Japan) for statistical analysis to compare the two groups and performed the chisquare test, Fisher's exact test, and Welch's $t$ test as needed. Univariate and multivariate logistic regression analyses were performed using SPSS (version 19; SPSS, Chicago, IL, USA). A $P$ value $<0.05$ was considered to be statistically significant.

- Fig.4 Deployment of a newly designed stent into the gallbladder.
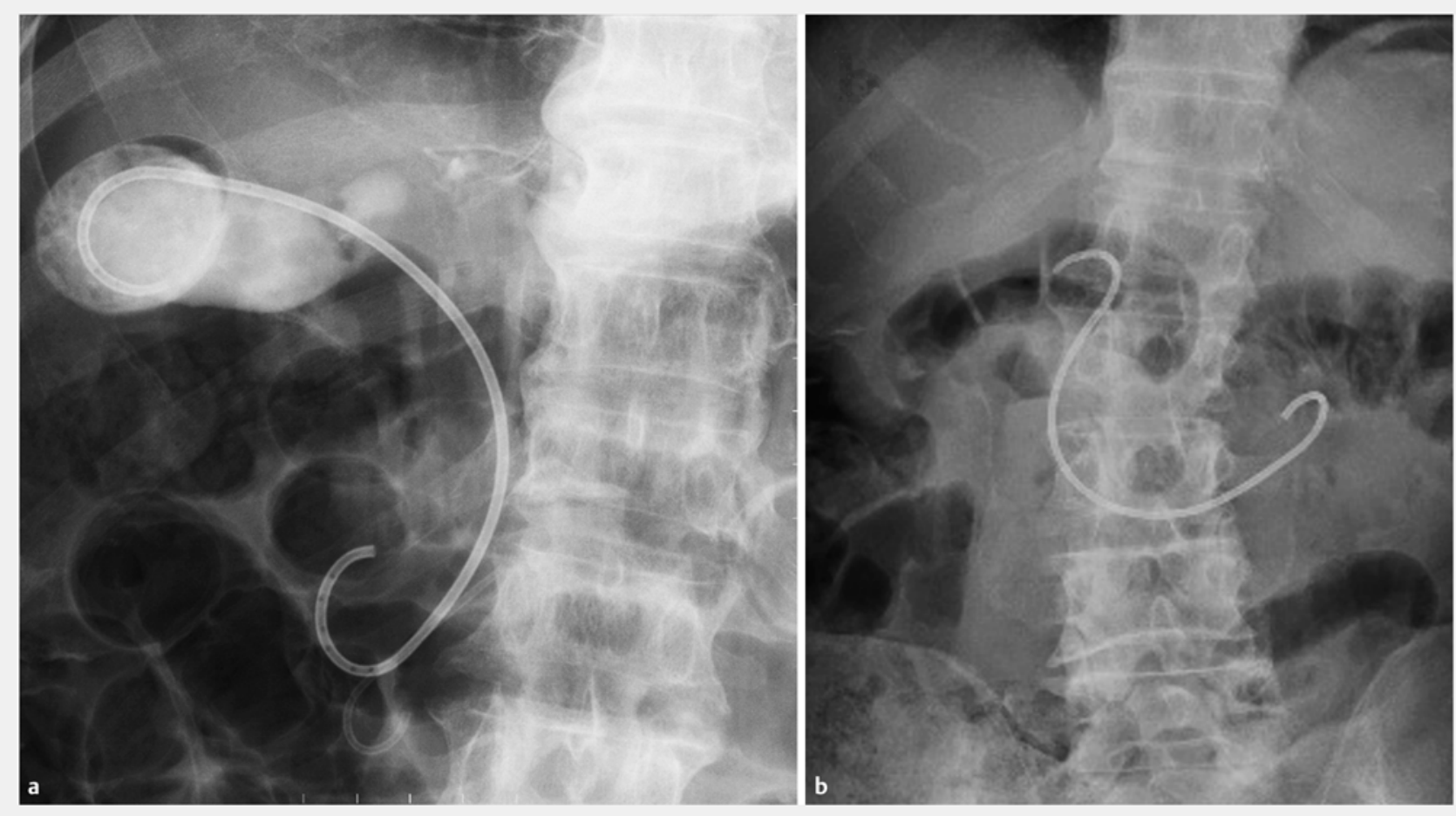

- Fig. 5 A case of stent migration in endoscopic gallbladder stenting using double-pigtail stent. a Immediately after stent placement. b At the time of stent migration. 


\section{Results}

\section{Patient backgrounds}

There was no significant difference between the novel stent group and the control groups in terms of age, sex, severity of cholecystitis, comorbidities (cholecystolithiasis, choledocholithiasis, malignant diseases), history of procedure for papilla of Vater, parapapillary diverticulum, or use of antithrombotic drugs (not significant; N.S.) ( $\triangleright$ Table 1 ).

\section{Details of endoscopic procedures}

- Table 2 show details of the endoscopic procedures. Patients in whom EST was performed before EGBS comprised $34.8 \%$ (8/ 23 ) of the novel stent group and $40.4 \%$ (19/47) of the control group, showing no difference (N.S.). Stent diameter and length used for EGBS were no different between the two groups (N.S.). Although there was no significant difference, the rate of endoscopic biliary drainage was slightly lower in the novel stent group [8.7\% (2/23) vs $23.4 \%(11 / 47), P=0.246]$. All endoscopic pancreatic stenting was performed to prevent post-ERCP pancreatitis.

\section{Technical and clinical success rates for EGBS}

In 70 patients in whom the GW and the tapered catheter could be inserted into the gallbladder before EGBS, the technical success rate for EGBS was $100 \%$ in both the novel stent and control groups.

The clinical success rate for acute cholecystitis was $100 \%$ $(23 / 23)$ in the novel stent group and $95.7 \%(45 / 47)$ in the control group, indicating no significant difference (N.S.) ( $\triangleright \mathrm{Ta}$ ble 3 ). The stents used in two patients in whom clinical improvement could not be obtained in the control group were both double-pigtail type $7 \mathrm{Fr}-15 \mathrm{~cm}$ long Advanix (Boston Scientific). In one patient, poor drainage due to a kink in the stent was improved by exchanging the stent with a double-pigtail 7 Fr-16 cm long SET-ERBD-72 stent (Hanaco Medical Co.). In the other patient, cholestasis at the papilla was due to stent placement without EST, and cholecystitis was improved by performing additional EST and endoscopic biliary stenting (EBS).

\section{Adverse events}

The details of AEs are shown in $>$ Table 3 . The rate of early AEs was $13.0 \%(3 / 23)$ in the novel stent group and $17.0 \%(8 / 47)$ in the control group, indicating no significant difference (N.S.). In the novel stent group, early AEs included mild pancreatitis in one patient, EST bleeding in one, and obstructive jaundice in one. On the other hand, in the control group, there was mild

- Table 1 Patient characteristics.

\begin{tabular}{|c|c|c|c|}
\hline & Novel stent group & Control group & $P$ value \\
\hline No. of patients & 23 & 47 & \\
\hline Age $($ mean $\pm S D)$ & $73.0 \pm 10.8$ & $76.0 \pm 11.8$ & 0.308 \\
\hline Sex (male/female) & $12 / 11$ & $27 / 20$ & 0.677 \\
\hline \multicolumn{4}{|l|}{ Severity of cholecystitis } \\
\hline - Severe & 2 & 5 & 0.865 \\
\hline - Moderate & 12 & 21 & 0.555 \\
\hline - Mild & 9 & 21 & 0.659 \\
\hline Cholecystolithiasis & 21 & 40 & 0.728 \\
\hline Choledocholithiasis & 7 & 17 & 0.635 \\
\hline Malignant diseases & 4 & 6 & 0.876 \\
\hline Malignant biliary stricture & 1 & 3 & 0.839 \\
\hline Previous procedures for papilla & 4 & 10 & 0.949 \\
\hline - EST & 3 & 7 & 0.876 \\
\hline - EPBD & 0 & 2 & 0.810 \\
\hline - Pre-cut & 1 & 0 & 0.713 \\
\hline - Pre-cut+EPBD & 0 & 1 & 0.713 \\
\hline Papillary diverticulum & 10 & 23 & 0.667 \\
\hline Use of antithrombotic drug & 7 & 13 & 0.809 \\
\hline
\end{tabular}


- Table 2 Endoscopic procedures.

\begin{tabular}{|c|c|c|c|}
\hline & Novel stent group & Control group & $P$ value \\
\hline No. of patients & 23 & 47 & \\
\hline \multicolumn{4}{|l|}{ Endoscopic procedure for papilla } \\
\hline - EST & 8 & 19 & 0.649 \\
\hline - No & 15 & 28 & \\
\hline \multicolumn{4}{|l|}{ Endoscopic gallbladder stenting } \\
\hline - Novel stent & 23 & 0 & \\
\hline - Pigtail type & 0 & 35 & \\
\hline - Straight type & 0 & 12 & \\
\hline - Caliber of stent ( $7 \mathrm{Fr} / 5 \mathrm{Fr})$ & $23 / 0$ & $46 / 1$ & 0.713 \\
\hline Length of stent $(\leq 15 \mathrm{~cm} / \geq 16 \mathrm{~cm})$ & $18 / 5$ & $33 / 14$ & 0.477 \\
\hline Common bile duct stone removal & 5 & 9 & 0.949 \\
\hline Biliary drainage & 2 & 11 & 0.246 \\
\hline ENBD & 1 & 3 & 0.839 \\
\hline EBS & 1 & 8 & 0.268 \\
\hline Pancreatic stenting & 4 & 11 & 0.790 \\
\hline
\end{tabular}

- Table 3 Clinical outcomes and adverse events.

\begin{tabular}{|c|c|c|c|}
\hline & Novel stent group & Control group & $P$ value \\
\hline No. of patients & 23 & 47 & \\
\hline Clinical success (\% (n)) & $100(23)$ & $95.7(45)$ & 0.810 \\
\hline \multicolumn{4}{|l|}{ Adverse events } \\
\hline - Early ( $\leq 7$ days) $(\%(n))$ & $13.0(3)$ & $17.0(8)$ & 0.936 \\
\hline - Pancreatitis (n) & 1 & 2 & \\
\hline - EST bleeding (n) & 1 & 1 & \\
\hline - Obstructive jaundice (n) & 1 & 3 & \\
\hline - Cystic duct perforation (n) & 0 & 1 & \\
\hline - Kink of stent (n) & 0 & 1 & \\
\hline - Delay (>7 days) (\% (n)) & $4.3(1)$ & $40.4(19)$ & 0.004 \\
\hline - Stent distal migration (n) & 0 & 15 & 0.006 \\
\hline - Cholecystitis (n) & 0 & 4 & 0.372 \\
\hline - Liver abscess (n) & 1 & 0 & 0.713 \\
\hline - Total (\% (n)) & $17.4(4)$ & $57.4(27)$ & 0.004 \\
\hline Follow-up period (mean \pm SD (range) days) & $120 \pm 143(4-573)$ & $162 \pm 252(4-950)$ & 0.371 \\
\hline
\end{tabular}

pancreatitis in two patients, EST bleeding in one, obstructive jaundice in three, cystic duct perforation in one, and a stent kink in one. Among the two groups, obstructive jaundice in four patients was caused by cholestasis at the papilla because of stent placement without EST, and additional EBS and/or EST led to improvement. All early AEs were improved by conservative therapy or endoscopic procedures. 
- Table 4 Comparison of the adverse events for each type of stents.

\begin{tabular}{|c|c|c|c|c|c|c|}
\hline & \multirow{2}{*}{$\begin{array}{l}\text { Novel stent } \\
(n=23)\end{array}$} & \multirow{2}{*}{$\begin{array}{l}\text { Pigtail stent } \\
(n=35)\end{array}$} & \multirow{2}{*}{$\begin{array}{l}\text { Straight stent } \\
(n=12)\end{array}$} & \multicolumn{3}{|l|}{$P$ value } \\
\hline & & & & $N$ vs $P$ & $\mathrm{~N}$ vs $\mathrm{S}$ & P vs S \\
\hline \multicolumn{7}{|l|}{ Adverse events (\% (n)) } \\
\hline - Early ( $\leq 7$ days) & $13.0(3)$ & $17.1(6)$ & $16.7(2)$ & 0.959 & 0.827 & 0.684 \\
\hline - Delay (>7 days) & $4.3(1)$ & $31.4(11)$ & $66.7(8)$ & 0.031 & $<0.001$ & 0.071 \\
\hline - Stent distal migration & $0(0)$ & $25.7(9)$ & $50.0(6)$ & 0.023 & 0.001 & 0.231 \\
\hline - Cholecystitis & $0(0)$ & $5.7(2)$ & $16.7(2)$ & 0.666 & 0.212 & 0.566 \\
\hline - Liver abscess & $4.3(1)$ & $0(0)$ & $0(0)$ & 0.831 & 0.737 & - \\
\hline - Total & $17.4(4)$ & $48.6(17)$ & $83.3(10)$ & 0.033 & $<0.001$ & 0.078 \\
\hline Follow-up period (mean $\pm S D$, days) & $120 \pm 143$ & $180 \pm 270$ & $112 \pm 190$ & 0.276 & 0.899 & 0.349 \\
\hline Time periods to migrate (mean \pm SD, days) & - & $84 \pm 84$ & $68 \pm 52$ & - & - & 0.656 \\
\hline
\end{tabular}

Rates of late AEs during the observation period [novel stent group, $120 \pm 143$ days; control group, $162 \pm 252$ days (mean \pm SD); $P=0.371]$ were $4.3 \%(1 / 23)$ in the novel stent group and $40.4 \%(19 / 47)$ in the control group, indicating a significantly higher rate in the control group $(P=0.004)$. Details of late AEs were liver abscess in one patient in the novel stent group and stent distal migration in 15 and recurrence of cholecystitis in four in the control group. The rate of stent distal migration in the control group was high (31.9\% (15/47)), which was significantly higher than that in the novel stent group $(P=0.006)$. In addition, stent migration was the cause of recurrence of cholecystitis in four patients in the control group.

The total rate of combined early and late AEs was $17.4 \%$ (4/ 23 ) in the novel stent group and $57.4 \%$ (27/47) in the control group, indicating a significantly higher rate in the control group $(P=0.004)$.

A comparison of AEs for each type of stents is shown in $\nabla$ Table 4. Although there was no difference in early AEs among novel, pigtail, and straight stents, the novel stent had significantly lower rates of late AEs and stent distal migration compared with the other stents. Among the three stent types, the straight stent had the highest rates of late AEs and stent distal migration. Mean duration from stent placement to migration in the control group was $69.5 \pm 69.0$ days (mean $\pm S D$ ). There was no difference in time from stent placement to migration between pigtail and straight stents (N.S.).

\section{Risk factors for stent distal migration}

Univariate and multivariate logistic regression analyses were performed to identify risk factors for stent distal migration. Univariate analysis identified straight type stent as the only significant risk factor for stent distal migration $[P=0.016$; odds ratio (OR), 5.44; 95\% confidence interval (CI), 1.43-20.72]. Moreover, the newly designed stent significantly correlated with a lack of migration ( $P=0.001$; OR, 0.58 ; $95 \% \mathrm{Cl}, 0.47$ 0.73 ) ( $\triangleright$ Table 5). Multivariate analysis also identified straight type stent as significant risk factor for stent distal migration ( $P$ $=0.011 ; \mathrm{OR}, 8.81 ; 95 \% \mathrm{Cl}, 1.66-46.83)(\triangleright$ Table 6$)$.

\section{Discussion}

Although ETGBD with ENGBD or EGBS is an effective alternative method when emergency cholecystectomy and PTGBD are considered high risk [1-5], ETGBD is technically difficult. In the last 10 years, the technical success rate is reported to be $64 \%$ to $96 \%$ [5-9, $12-20]$. ETGBD's technical difficulty is associated with the inherent complexity of inserting the GW into the gallbladder. Moreover, even when GW placement in the gallbladder is successful, subsequent placement of the stent may be complicated. In this study, if a 7-Fr tapered catheter could be inserted into the gallbladder before stent insertion, the technical success rate was $100 \%$ for both novel stent and control groups. With this approach of insertion of a tapered catheter into the gallbladder before stent placement, cystic duct bougie can be achieved and subsequent insertion of any stent is expected to improve. In addition, we consider successful insertion of a tapered catheter as predictive of subsequent success of stent placement. Theoretically, the longer, tortuous tip of the novel stent might be an obstacle to pushing the stent and it may be inferred that it is harder to insert than standard stents. However, using the novel stent, it was not hard to insert into the gallbladder compared with standard stents. The tapered tip and relatively hard shaft of the novel stent may contribute to good insertability. We acknowledge that the stent may have been easy to place in the cases in this study because no cases were included in which the $7 \mathrm{Fr}$ tapered catheter could not be inserted into the gallbladder.

Clinical success rates with ETGBD for acute cholecystitis are reported to be $83 \%$ to $100 \%$ in per-protocol analyses [5-9, 12 21]. It has also been reported that the clinical success rate with ETGBD is roughly $10 \%$ lower than the technical success rates in intention-to-treat analysis because of the accumulation of 
- Table 5 Risk factors for stent distal migration (univariate analysis).

\begin{tabular}{|c|c|c|c|c|}
\hline & Migration (+) & Migration (-) & $P$ value & OR (95\%Cl) \\
\hline No. of patients & 15 & 55 & & \\
\hline Age $(>80)$ & 4 & 24 & 0.373 & $0.470(0.133-1.660)$ \\
\hline Sex (female) & 7 & 24 & 1.000 & $1.130(0.359-3.555)$ \\
\hline Novel stent & 0 & 23 & 0.001 & $0.582(0.465-0.728)$ \\
\hline Pigtail stent & 9 & 26 & 0.561 & $1.637(0.524-5.341)$ \\
\hline Straight stent & 6 & 6 & 0.016 & $5.444(1.431-20.716)$ \\
\hline Length of stent $(<12 \mathrm{~cm})$ & 4 & 5 & 0.091 & $3.636(0.838-15.782)$ \\
\hline Severe cholecystitis & 2 & 5 & 0.637 & $1.538(0.267-8.850)$ \\
\hline Acalculous cholecystitis & 2 & 7 & 1.000 & $1.055(0.195-5.699)$ \\
\hline Malignant biliary stricture & 0 & 4 & 0.571 & $0.927(0.861-0.999)$ \\
\hline Post-EST papilla & 8 & 29 & 1.000 & $1.025(0.326-3.217)$ \\
\hline Biliary drainage & 2 & 11 & 0.720 & $0.615(0.121-3.137)$ \\
\hline Pancreatic stenting & 4 & 11 & 0.723 & $1.455(0.388-5.453)$ \\
\hline Papillary diverticulum & 5 & 28 & 0.258 & $0.482(0.146-1.595)$ \\
\hline
\end{tabular}

- Table 6 Risk factors for stent distal migration (multivariate analysis).

\begin{tabular}{|l|l|l|}
\hline & P value & OR (95 \%Cl) \\
\hline Age (>80) & 0.177 & $0.343(0.073-1.621)$ \\
\hline Sex (female) & 0.726 & $1.297(0.303-5.556)$ \\
\hline Stent type (straight) & $\mathbf{0 . 0 1 1}$ & $\mathbf{8 . 8 0 5}(\mathbf{1 . 6 5 6 - 4 6 . 8 2 6})$ \\
\hline Length of stent $(<12 \mathrm{~cm})$ & 0.107 & $4.738(0.715-31.406)$ \\
\hline Severe cholecystitis & 0.537 & $1.862(0.259-13.367)$ \\
\hline Acalculous cholecystitis & 0.987 & $1.019(0.106-9.806)$ \\
\hline Post-EST papilla & 0.770 & $1.247(0.284-5.476)$ \\
\hline Biliary drainage & 0.419 & $0.450(0.065-3.123)$ \\
\hline Pancreatic stenting & 0.230 & $3.213(0.478-21.622)$ \\
\hline Papillary diverticulum & 0.313 & $0.459(0.101-2.084)$ \\
\hline OR, odds ratio; Cl, confidence interval; EST, endoscopic sphincterotomy
\end{tabular}

purulent material, sludge, or gallstones, thus hindering effective drainage $[13,22,23]$. In this study, clinical success rates for cases in which EGBS was technically successful were $100 \%$ in the novel stent group and $95.7 \%$ in the control group, which are both extremely favorable. Suctioning viscous bile and irrigation of the gallbladder with saline through a tapered catheter prior to stent placement may have contributed to this favorable outcome.

EGBS-specific early AEs include cystic duct perforation, stent kinking, and obstructive jaundice without EST. In subjects un- dergoing EGBS, EST often cannot be performed because of abnormal coagulation; however, stent placement without EST could lead to outflow obstruction of bile at the papilla. Therefore, with the novel stent, side holes were opened at the shaft in anticipation of bile drainage from the common bile duct. However, there was one case of obstructive jaundice due to cholestasis in the novel stent group and the efficacy of the side hole at the shaft was unclear.

In this study, the rate of late AEs in the control group was high (40.4\%), and the rate of stent distal migration was quite high at $31.9 \%$. Moreover, in four patients who developed acute cholecystitis in the control group, the cause was stent distal migration. According to previous reports, stent distal migration not only causes exacerbation or recurrence of cholecystitis but also leads to severe complications such as pancreatitis [24] and intestinal perforation $[25,26]$. Therefore, especially in cases of long-term stent placement, stent selection should be performed with prevention of migration in mind. In this study, univariate analysis indicated that a straight stent was the risk factor associated with migration; thus, straight stents should be avoided for long-term placement of EGBS. Inoue et al. [19] reported good long-term outcomes using a newly designed stent that was straight stent on the distal side and a small half-pigtail one on the proximal side (stent migration: $0 \%$ [0/23], cholecystitis recurrence: $0 \%$ [0/23], cholangitis: $4.3 \%$ [1/23]). Thus, we assumed that a straight stent might be associated with less migration than a double-pigtail type, and we used straight stents for a while. However, results from this study show that stents that are straight on both proximal and distal sides often migrate. 
In addition, the high rate of stent migration compared with previous reports may be related to the definition of stent migration. We defined stent distal migration not only as when a stent migrated to the intestine or out of the body but also when a large part of the tip slipped out of the gallbladder. Therefore, especially with a pigtail stent, we termed a stent as having migrated when only its tip was caught in the neck of gallbladder or cystic duct ( $\$$ Fig. 5 ). In previous reports, there are no detailed descriptions of the definition of stent migration, but when the tip of the stent was caught in the neck of gallbladder or cystic duct, it may not have been judged as a migration.

Remarkably, there was no stent distal migration in the novel stent group. We assume that the factors that contributed to prevention of stent migration include: (1) the three-dimensional spiral shape of the stent tip; (2) the maximum stent length of $19 \mathrm{~cm}$, allowing for placement at a sufficient depth; (3) the semicircular shape of the stent shaft reducing the stent's axial force; and (4) the straight distal end of the stent, meaning that it is less affected by food passing and intestinal peristalsis. We believe that among these factors, the semicircular shape of the stent shaft was the most effective in preventing stent migration. Standard biliary stents have a straight shaft, which requires bending when placed in the gallbladder to accommodate the regional anatomy. Therefore, a straight shaft must create a strong axial force $[27,28]$. We consider that the semicircular shape of the stent with low axial force contributes to prevention of migration. Although the basic policy in this study was to place the stent tip at the fundus of the gallbladder in both the novel stent group and the control group, there may be more cases in which the stent can be inserted to the target site because of the longer lengths available. Moreover, multivariate analysis in this study revealed that the straight stent was a risk factor for migration. Although the distal end of the novel stent is straight, there were no cases of migration in the novel stent group. It is apparent that when only the distal end is straight, it is not a risk factor for migration.

Several limitations of this study exist. First, the design is single-center and retrospective. In addition, although there were no statistical differences and the novel stent group had a slightly shorter observation period compared with the control group [120 \pm 143 vs $162 \pm 252$ (mean, days)]. However, because the observation period of the novel stent group was longer than the mean duration from placement to migration in the control group [69.5 \pm 69.0 (mean, days)], we believe that evaluation was sufficient. To resolve these limitations, comparison and verification of the novel stent and traditional stents with a randomized controlled trial are desirable in the future.

\section{Conclusion}

In conclusion, EGBS using the novel stent (GBest-N stent) led to good results for technical and clinical success, and AEs. In terms of technical and clinical success and early AEs, EGBS was effective for acute cholecystitis regardless of whether the traditional or novel stent was used. However, in terms of long-term outcomes, stent distal migration and associated recurrence of cholecystitis occur frequently with the traditional biliary stent. The novel stent had significantly lower rates of late AEs and stent distal migration compared with the traditional biliary stent. Thus, if long-term stent placement is necessary, the novel stent is more effective.

\section{Competing interests}

None

\section{References}

[1] Kozarek RA et al. Selective cannulation of the cystic duct at time of ERCP. J Clin Gastroenterol 1984; 6: 37-40

[2] Feretis CB, Manouras A], Apostolidis NS et al. Endoscopic transpapillary drainage of gallbladder empyema. Gastrointest Endosc 1990; 36 $523-525$

[3] Tsuyuguchi T, Itoi T, Takada T et al. TG13 indications and techniques for gallbladder drainage in acute cholecystitis (with videos). J Hepatobiliary Pancreat Sci 2013; 20: 81 -88

[4] Mori Y, Itoi T, Baron TH et al. Tokyo Guidelines 2018: management strategies for gallbladder drainage in patients with acute cholecystitis (with videos). J Hepatobiliary Pancreat Sci 2018; 25: 87-95

[5] Itoi T, Sofuni A, Itokawa F et al. Endoscopic transpapillary gallbladder drainage in patients with acute cholecystitis in whom percutaneous transhepatic approach is contraindicated or anatomically impossible (with video). Gastrointest Endosc 2008; 68: 455-460

[6] Itoi T, Kawakami H, Katanuma A et al. Endoscopic nasogallbladder tube or stent placement in acute cholecystitis: a preliminary prospective randomized trial in Japan (with videos). Gastrointest Endosc 2015; 81: $111-118$

[7] Yang M], Yoo BM, Kim JH et al. Endoscopic naso-gallbladder drainage versus gallbladder stenting before cholecystectomy in patients with acute cholecystitis and a high suspicion of choledocholithiasis: a prospective randomised preliminary study. Scand J Gastroenterol 2016; 51: $472-478$

[8] Khan MA, Atiq O, Kubiliun N et al. Efficacy and safety of endoscopic gallbladder drainage in acute cholecystitis: Is it better than percutaneous gallbladder drainage? Gastrointest Endosc 2017; 85: 76-87

[9] Mutignani M, lacopini F, Perri V et al. Endoscopic gallbladder drainage for acute cholecystitis: technical and clinical results. Endoscopy 2009; 41: $539-546$

[10] Yokoe M, Takada T, Strasberg SM et al. TG13 diagnostic criteria and severity grading of acute cholecystitis (with videos). J Hepatobiliary Pancreat Sci 2013; 20: 35-46

[11] Cotton PB, Lehman G, Vennes J et al. Endoscopic sphincterotomy complications and their management: an attempt at consensus. Gastrointest Endosc 1991; 37: 383-393

[12] Ogawa O, Yoshikumi H, Maruoka $\mathrm{N}$ et al. Predicting the success of endoscopic transpapillary gallbladder drainage for patients with acute cholecystitis during pretreatment evaluation. Can J Gastroenterol 2008; 22: $681-685$

[13] Itoi T, Coelho-Prabhu N, Baron TH. Endoscopic gallbladder drainage for management of acute cholecystitis. Gastrointest Endosc 2010; 71: $1038-1045$

[14] Lee TH, Park DH, Lee SS et al. Outcomes of endoscopic transpapillary gallbladder stenting for symptomatic gallbladder diseases: a multicenter prospective follow-up study. Endoscopy 2011; 43: 702 - 708

[15] Maekawa S, Nomura R, Murase T et al. Endoscopic gallbladder stenting for acute cholecystitis: a retrospective study of 46 elderly patients aged 65 years or older. BMC Gastroenterol 2013; 13: 65 
[16] Yane K, Maguchi H, Katanuma A et al. Feasibility, efficacy, and predictive factors for the technical success of endoscopic nasogallbladder drainage: a prospective study. Gut Liver 2015; 9: 239-246

[17] McCarthy ST, Tujios S, Fontana RJ et al. endoscopic transpapillary gallbladder stent placement is safe and effective in high-risk patients without cirrhosis. Dig Dis Sci 2015; 60: 2516-2522

[18] Widmer J, Alvarez P, Sharaiha RZ et al. endoscopic gallbladder drainage for acute cholecystitis. Clin Endosc 2015; 48: 411-420

[19] Inoue T, Okumura F, Kachi K et al. Long-term outcomes of endoscopic gallbladder stenting in high-risk surgical patients with calculous cholecystitis (with videos). Gastrointest Endosc 2016; 83: 905-913

[20] Doi S, Yasuda I, Mabuchi M et al. Hybrid procedure combining endoscopic gallbladder lavage and internal drainage with elective cholecystectomy for acute cholecystitis: A prospective pilot study (The BLADE study). Dig Endosc 2018 Jul30: 501 - 507

[21] Itoi T, Takada T, Hwang TL et al. Percutaneous and endoscopic gallbladder drainage for acute cholecystitis: international multicenter comparative study using propensity score-matched analysis. J Hepatobiliary Pancreat Sci 2017; 24: $362-368$

[22] Lee DW, Chan AC, Lam YH et al. Biliary decompression by nasobiliary catheter or biliary stent in acute suppurative cholangitis: a prospective randomized trial. Gastrointest Endosc 2002; 56: 361-365
[23] Park SY, Park CH, Cho SB et al. The safety and effectiveness of endoscopic biliary decompression by plastic stent placement in acute suppurative cholangitis compared with nasobiliary drainage. Gastrointest Endosc 2008; 68: 1076-1080

[24] Yane K, Katanuma A, Maguchi H. Late onset pancreatitis 6 months after endoscopic transpapillary gallbladder stenting for acute cholecystitis. Dig Endosc 2014; 26: 494 - 495

[25] Siaperas P, loannidis A, Skarpas A et al. A rare cause for Hartmann's procedure due to biliary stent migration: A case report. Int J Surg Case Rep 2017; 31: $83-85$

[26] Mady RF, Niaz OS, Assal MM. Migrated biliary stent causing perforation of sigmoid colon and pelvic abscess. BMJ Case Rep 2015: doi:10.1136/bcr-2014-206805

[27] Isayama H, Nakai Y, Toyokawa Y et al. Measurement of radial and axial forces of biliary self-expandable metallic stents. Gastrointest Endosc 2009; 70: $37-44$

[28] Isayama H, Nakai Y, Hamada T et al. Understanding the mechanical forces of self-expandable metal stents in the biliary ducts. Curr Gastroenterol Rep 2016; 18: 64 